\title{
UNFAVOURABLE VISUAL ENVIRONMENT IN LARGE CITY PROMOTES THE DEVELOPMENT OF AGGRESSIVENESS IN SCHOOLCHILDREN.
}

\author{
N. Kozelko, E. Tolstaya. \\ Belorussian State University - International Sakharov State Environmental Institute, Faculty of Envi- \\ ronmental Medicine, Minsk, Belarus.
}

Changes in mental health has been revealed in population living in large cities during last decades. From the point of view of visual ecology aggressive and homogenic fields in modern cities and rooms provoke development of psychological distress, mainly aggressiveness.

Objectives: The aim of this study was to compare the signs of psychological distress in schoolchildren living in Minsk city and small towns.

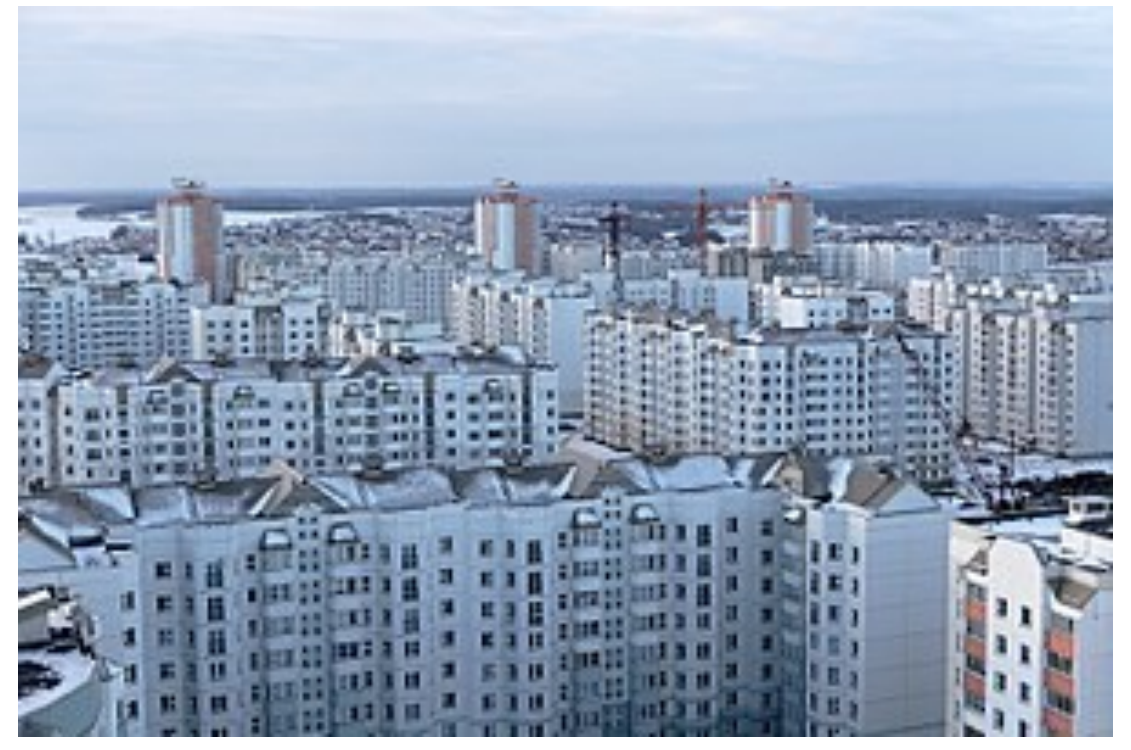

Fig. 1. An example of a homogeneous field. District of Minsk Kamennaya Horka.

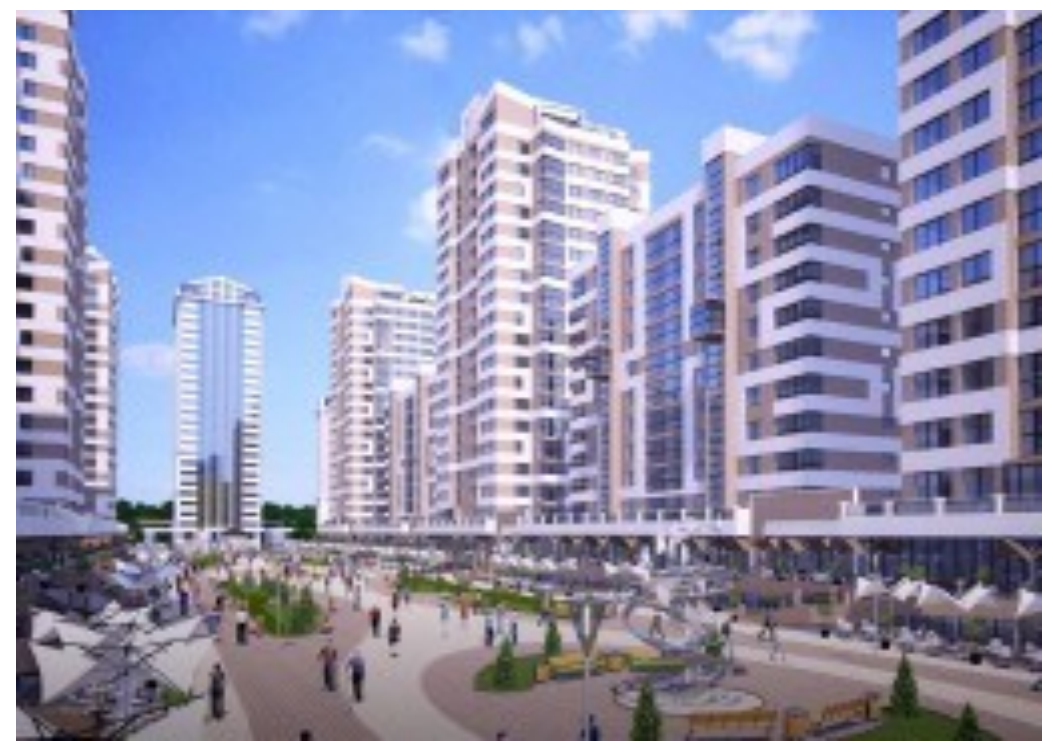

Fig. 2. An example of an aggressive field. District "Lighthouse of Minsk".

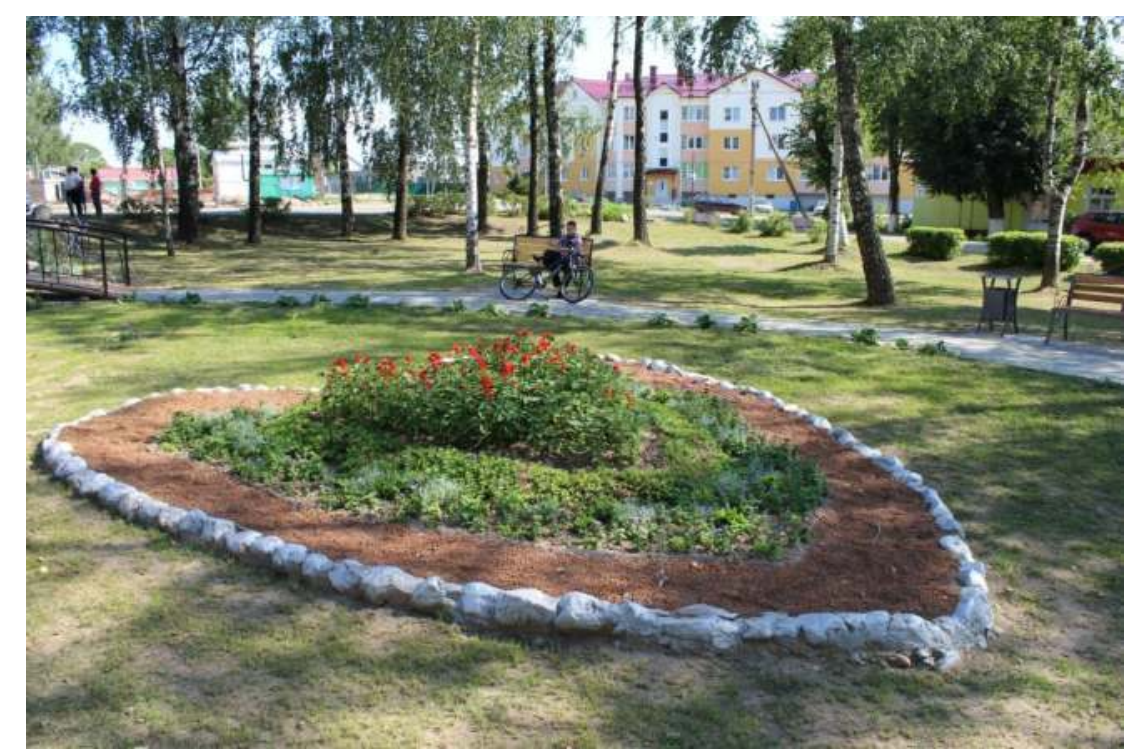

Fig. 3. An example of the visual environment of the satellite city Rudensk.

\section{Materials and Methods:}

485 schoolchildren (14 - 15 years old) living in Minsk city (313 teenagers) and 2 small towns of Belarus had been examined with Spilberger Trait Anxiety Inventory, Buss-Durkee Hostility Inventory, Beck Depression Inventory.

\section{Results:}

Results: No difference in levels of trait anxiety and depression between schoolchildren living in Minsk and small towns has been noticed. 47.2\% of all adolescents had high levels of trait anxiety. But teenagers living in city Minsk had distinctly higher levels of aggressiveness, negativity and irritation and the tendency of increasing physical aggressiveness level. Then we have compared examined indexes between groups of schoolchildren from Minsk studying in favourable visual environment and in unfavourable one. The distinctly higher level of physical aggressiveness and the tendency of increasing verbal aggressiveness level in group studying in unfavourable visual environment have been noticed.

Conclusions: schoolchildren from large Minsk city had distinctly higher levels of aggressiveness, negativity and irritation then from small towns and one of the factors of their promotion is unfavourable visual environment. 